\title{
Comparison of two different doses of Epidural Butorphanol in Lower Limb Orthopedic Surgery
}

\author{
Kujur S. ${ }^{1}$, Kosam D. ${ }^{2}$ \\ ${ }^{1}$ Dr. Shweta Kujur, Assistant Professor, Department of Anesthesiology and Critical Care, Chhattisgarh Institute of \\ Medical Sciences, Bilaspur (C.G), ${ }^{2}$ Dr. Durga Kosam, Associate Professor, Department of Anesthesiology, Government \\ Medical College, Rajnandgaon (C.G.) India.
}

Corresponding Author: Dr. Durga Kosam, Associate Professor, Department of Anesthesiology, Government Medical College, Rajnandgaon (C.G.) India. E-mail: kosamdurga@gmail.com

\begin{abstract}
Introduction: Epidural and spinal anaesthesia both are effective alternative to general anaesthesia when surgical site is located in lower extremities. When post operative analgesia is required epidural anaesthesia is the choice. This study was conducted to assess the effect of Butorphanol added to local anaesthetic via epidural route and to optimize the dose of Butorphanol via epidural route i.e. $2 \mathrm{mg}$ and $3 \mathrm{mg}$ and to observe the duration of postoperative analgesia with two different doses. Methodology: A randomized control study was conducted on 40 ASA I \& II patients of either sex aged 18-60 yrs undergoing lower limb orthopedic surgery under epidural anesthesia. The patients were randomly allocated into two equal groups. Group A received $2 \mathrm{mg}$ of Butorphanol along with local anaesthetic solution and Group B received $3 \mathrm{mg}$ of Butorphanol along with local anaesthetic. The onset and peak effect of sensoryand motor block, level of sedation, hemodynamic changes and duration of postoperative analgesia and complications, if any were observed. Results: For sensory effect, onset was $25 \pm 7.07 \mathrm{sec}$ and peak effect $312.5 \pm 12.4 \mathrm{sec}$ in Group A patients as compared to Group B where it was $12.81 \pm 21.68 \mathrm{sec}$ and $162.8 \pm 21.68 \mathrm{sec}$ respectively, which is statistically significant $(\mathrm{P}<0.05)$. For motor effect onset was 3.5 $\pm 1.01 \mathrm{~min}$ and peak effect $11.4 \pm 3.91 \mathrm{~min}$ in Group A patients as compared to Group B patients where it was $2.7 \pm 0.67 \mathrm{~min}$ and $6.09 \pm 0.97 \mathrm{~min}(\mathrm{P}<0.05)$. Hemodynamics remained stable and comparable in both the groups $(\mathrm{P}>0.05)$. Duration of postoperative analgesia according to VAS, pain relief in Group A patients was up to 8 hrs and in Group B it was up to 12 hours and rescue analgesia required only after $12 \mathrm{hrs}(\mathrm{P}<0.05)$. Conclusion: Newer synthetic opioid- Butorphanol can be used along with local anaestheticsolution via epidural route in lower limb surgeries with effective intraoperative sedation and prolonged postoperative analgesia without fear of nausea/vomiting and respiratory depression.
\end{abstract}

Key words: Butorphanol, Epidural anesthesia, Local anesthetics, Orthopedic surgery

\section{Introduction}

Epidural anaesthesia provides early postoperative mobilization and rehabilitation with minimal pain and discomfort. This advantage of epidural anaesthesia is needed in modern orthopedic surgery.

It has properties of central neuraxial blockade. It abolishes stress response to surgery, requires least manpower, reduced incidence of nausea and vomiting, decreased bleeding during surgery, deceased incidence of thrombo-embolic events and decrease use of postoperative analgesia [1].

Manuscript received: $27^{\text {th }}$ September 2018

Reviewed: $7^{\text {th }}$ October 2018

Author Corrected: $15^{\text {th }}$ October 2018

Accepted for Publication: $20^{\text {th }}$ October 2018
Butorphanol, synthetic opioid is a strong $\mathrm{k}$ receptor agonist, a weak $\mu$ receptor agonist-antagonist and is relatively lipid soluble. It produces less respiratory depression and a reduced incidence of pruritus, nausea and vomiting which is a common phenomenon with morphine [2]. In this study we added Butorphanol to local anestheticsto assess the efficacy of Butorphanol and to optimize the dose of Butorphanol via epidural route i.e. 2 and $3 \mathrm{mg}$ and toobserve the duration of postoperative analgesia with two different doses. 


\title{
Methodology
}

This randomized prospective study was carried out at department of Anaesthesiology Chhattisgarh Institute of Medical Sciences, Bilaspur (C.G.). 40 patients of either sex, aged 18-60 yrs of ASA (American society of anesthesiologist) grade I or II undergoing lower limb orthopedic surgery were enrolled for study.

Exclusion criteria: Patients with history of drug abuse, respiratory and neurological disorder, bleeding disorder, patients on MAO inhibitors were excluded from the study.

All patients were thoroughly examined during pre anaesthetic check up and investigated. Patients were randomly allocated to one of the following two groups in a double blind fashion based on a computer generated code. Group A received $2 \mathrm{mg}$ of injection Butorphenol along with local anaesthetic solution. Group B received $3 \mathrm{mg}$ of injection Butorphenol along with local anaesthetic solution. Patients were kept nil orally 8 hours prior to induction. In the operating room, monitoring devices were attached which included heart rate, electrocardiograph (ECG), pulse oximeter (SPO2), non invasive blood pressure (NIBP), respiratory rate. Baseline parameters were recorded, an intravenous line was secured and pre loading was done with Ringer lactate $10 \mathrm{ml} / \mathrm{kg}$.

Patients were administered epidural block with 18 gauge Touhy needle and catheter was secured 3-4 $\mathrm{cm}$ into the epidural space and test dose of $3 \mathrm{ml}$ of $2 \%$ Lignocaine hydrochloride solution containing adrenaline 1:200,000 was injected. After 4-6 minutes of administering the test dose epidural block was obtained with the local anaesthetic solution, which consisted of $20 \mathrm{ml}$ of equal volume of Lignocaine $2 \%$ with Adrenaline (1:200,000) and injection Bupivacaine 5\%. In group A along with local anaesthetic solution $2 \mathrm{mg}$ of injection Butorphenol was added while in group B along with local anaesthetic solution 3mg of injection Butorphenol was added.

Patients were observed for onset (dull sensation to pin prick or decreased pain at injury site) and peak effect (no sensation felt) of sensory and motor blockade, level of sedation (Table-1), time for maximum level achieved, duration of surgery and postoperative analgesia. Top up dose was given after $1.5 \mathrm{hrs}$ as half the initial dose. Sensory effect was observed at intervals of 30sec, 1, 3, 6,9,12 and 15 minutes after completing the drug injection. Sedation was graded as shown in (Table-1). For the motor effect Bromage's criteria [3] were used at intervals of 5, 10,15,20,30 minutes. Onset was considered when there was grade 1 blockade and peak effect when the blockade was of grade 3.

Time for maximum level achieved was also noted. Patients were monitored for hemodynamics, $\mathrm{RR}$ and $\mathrm{SpO}_{2}$ at 5 , 10,15,30,60 minutes interval. Postoperatively patients were observed for pulse, B.P., VAS (visual analogue scale), analgesia score (Table 1) and complications if any at intervals of 2, 4,6,8,10,12 hrs. The data was complied systematically and analyzed using Analysis of variance and chi -square test. To compare the continuous variables between two groups SPSS version was used.

Table-1: Scores for sedation, motor and analgesia.

\section{Sedation score}

$0=$ No sedation

$1=$ Drowsy

$2=$ Asleep but arousable

$3=$ Asleep and not arousable

\section{Bromage's criteria}

$0=$ No motor block

$1=$ Partial block, able to flex knees

2 - Acceptable, unable to flex knees.

$3=$ Unable to move legs

\author{
Analgesia score (AS) \\ $1=$ No pain \\ $2=$ No pain at rest but duringvoluntary movement \\ $3=$ Pain at rest but tolerable \\ $4=$ Intolerable pain
}




\section{Results}

In our study, the demographic data (Table-2) of the both groups were comparable $(\mathrm{p}>0.05)$.

Table-2: Demographic data.

\begin{tabular}{|c|c|c|c|}
\hline Demographic Data & Group A & Group B & Significance \\
\hline Age (years) & $31.31 \pm 8.17$ & $41.22 \pm 11.44$ & P $>0.05$ \\
Nale & $13(65 \%)$ & $11(55 \%)$ & \\
\hline Female & $7(35 \%)$ & $9(45 \%)$ & \\
\hline ASA I & $11(55 \%)$ & $10(50 \%)$ & \\
\hline ASA II & $9(45 \%)$ & $10(50 \%)$ & \\
\hline Duration of surgery & $3.28 \pm 1.27$ & $3.16 \pm 1.08$ & \\
\hline
\end{tabular}

Onset time for sensory effect $(\mathrm{sec})$ in group A was $25 \pm 7.07$; while in group B it was faster i.e.12.81 $\pm 21.68(\mathrm{p}<0.05)$ (Table-3). Peak effect in group A was $312.5 \pm 12.4 \mathrm{sec}$, while in-group B it was $162.8 \pm 21.68(\mathrm{sec})(\mathrm{p}<0.05)$. For the motor blockade onset time (minutes) and peak effect in-group A was 3.5 \pm 1.01 and $11.4 \pm 3.91$ respectively while in group B it was $2.7 \pm 0.67$ and $6.09+0.97(\mathrm{p}<0.05)$. Thus, we observed faster onset as well as peak effect of both sensory and motor effect in group B patients as compared to group A patients.

Table-3: Sensory and Motor Blockade

\begin{tabular}{|c|c|c|c|c|}
\hline & & Group A & Group B & Significance \\
\hline \multirow[t]{2}{*}{ Sensory Blockade } & Onset (sec) & $25 \pm 7.07$ & $12.81 \pm 21.68$ & \multirow{4}{*}{$\begin{array}{c}\mathrm{p}<0.05 \\
\text { significant }\end{array}$} \\
\hline & Peak effect (sec) & $312.5 \pm 12.4$ & $162.8 \pm 21.68$ & \\
\hline \multirow[t]{2}{*}{ Motor Blockade } & Onset (min) & $3.5 \pm 1.01$ & $2.7 \pm 0.67$ & \\
\hline & Peak effect (min) & $11.4 \pm 3.91$ & $6.09 \pm 0.97$ & \\
\hline
\end{tabular}

Table- 4 shows the volume of drug $(\mathrm{ml})$ required, time for maximum level of sensory blockade achieved (minutes), duration of surgery (hrs) and top up dose requirement in both the groups and they were comparable $(\mathrm{P}>0.05)$.

Table-4: Volume of drug and maximum sensory blockade

\begin{tabular}{|c|c|c|c|}
\hline & Group A & Group B & Significance \\
\hline Volume of drug $(\mathrm{ml})$ & $23.31 \pm 2.25$ & $24.65 \pm 2.05$ & $\mathrm{P}<0.05$ \\
\cline { 1 - 3 } Time for maximumlevel (min) & $13.95 \pm 3.91$ & $11.25 \pm 3.91$ & \multirow{2}{*}{ Not significant } \\
\hline Top up dose $(\mathrm{ml})$ & $8.7 \pm 4.49$ & $8.01 \pm 4.45$ & \\
\hline
\end{tabular}

Table 5 shows sedation score. In group A 80\% of patients and ingroup B 85\% of patients had sedation score of 2 (asleep but arousable) $(\mathrm{p}>0.05)$.

Table- 5: Sedation Score

\begin{tabular}{|c|c|c|c|}
\hline Sedation score & Group A & Group B & Significance \\
\hline 0 & 0 & 0 & $\begin{array}{c}\text { P }<0.05, \\
\text { not significant }\end{array}$ \\
\hline 1 & $4(20 \%)$ & $3(15 \%)$ & \\
\hline 3 & $16(80 \%)$ & $17(85 \%)$ & \\
\hline
\end{tabular}

Graph 1 and 2 shows changes in pulse, systolic blood pressure and diastolic blood pressure of both the groups and it was not significant. Respiratory parameters (Graph 3) shows that there was significant fall in respiratory rate in both the groups, but it was never $<10 /$ min (a sign for respiratory depression) $(\mathrm{P}<0.05)$. Reading on pulse-oximetry as shown in graph 4 further supported this. 
Original Research Article
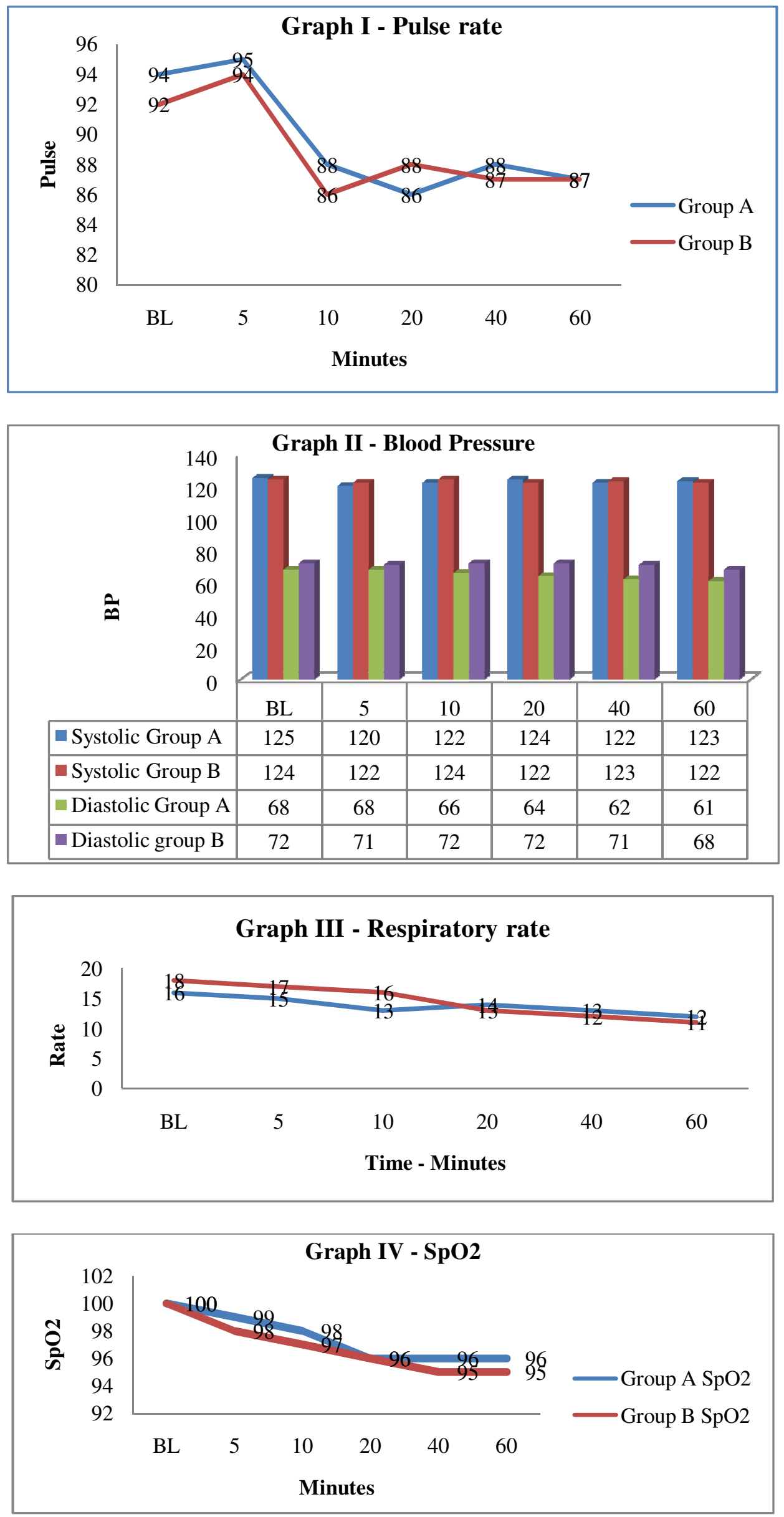
Evaluating the postoperative analgesia, according to visual analogue scale (graph 5), in group A $70 \%$ of patients had visual analogue scale of 3-5 up to $8 \mathrm{hrs}$ and $30 \%$ of patients had visual analogue scale of 6-8. In group B $80 \%$ of patients had visual analogue scale of $3-5$ up to $12 \mathrm{hrs}$ and $20 \%$ of patients had visual analogue scale of 6-8.
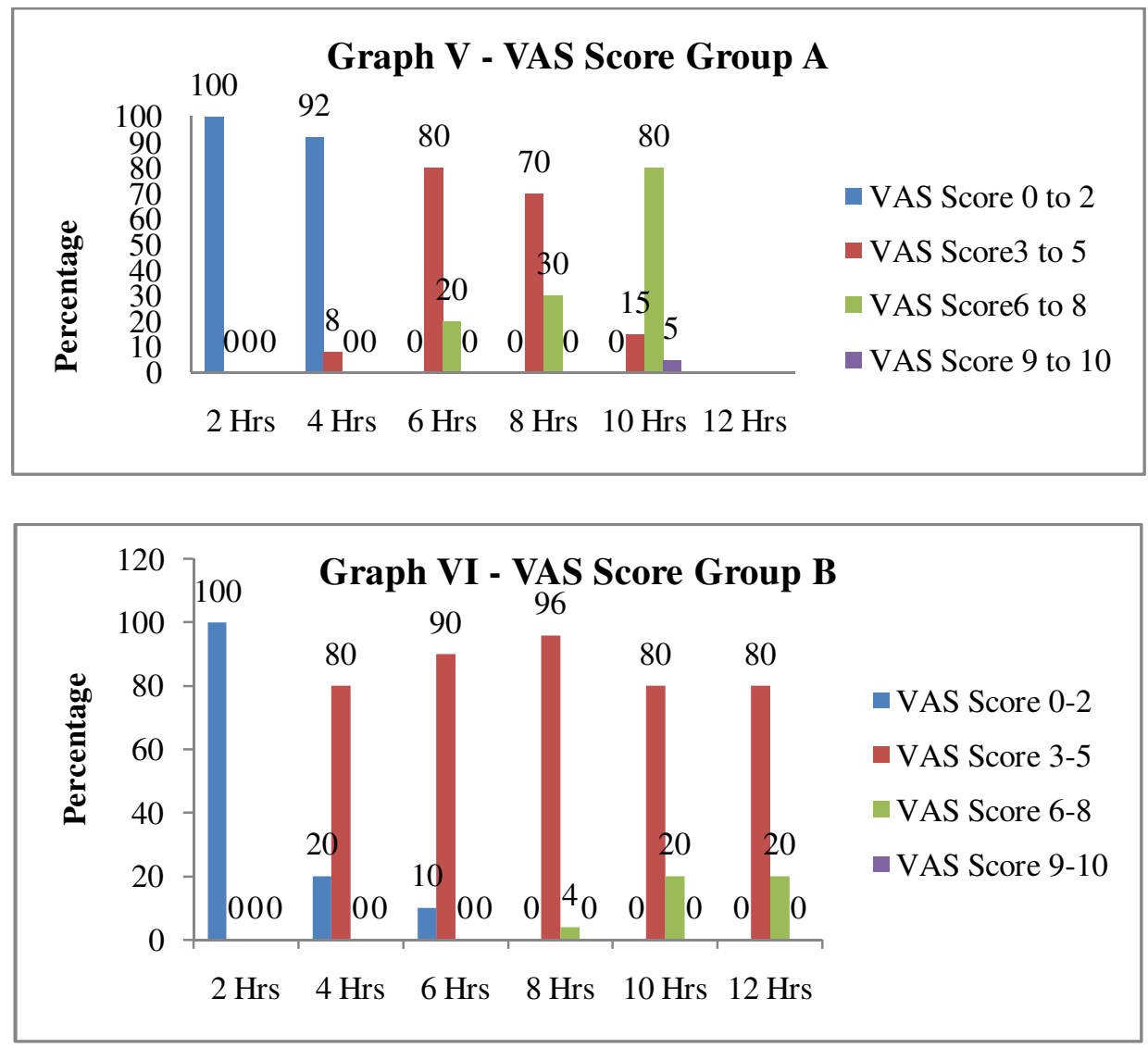

\section{Discussion}

Central neuraxial blockade is an important tool in the armamentarium of the anesthesiologists as the alterations in physiology and biochemistry and thereby morbidity and mortality brought about by central neuraxial blockade are minimal as compared to general anaesthesia. Subarachnoid block is the most popular and widely practiced technique all over the world. But there has been resurgence of interest even in the epidural blockade as it can be used alone or in combination with general anaesthesia and can be used for postoperative analgesia [1].

Opioids acting on spinal cord receptors provide distinct advantage over its systemic administration like the quality of analgesia is better, sedation is less, function is preserved and outcome is improved. Side effects are no more frequent or severe as compared to systemic opioids required to produce equivalent analgesia [4]. For epidural anaesthesia, we have used combination of local anesthetics and opioid. Local anesthetics act by producing a reversible blockade of sodium channels in nervous tissue preventing the transmission of electrical impulses and produce sympathetic blockade, while epidural opioids have their major site of action on preand post-synaptic receptors in the substantia gelatinosa of the dorsal horn producing selective block of nociceptive pathways. Studies have reported obtaining effective analgesia from the concomitant use of Morphine-Bupivacaine and Fentanyl-Bupivacaine continuous epidural infusions. Another rational for these combinations is to reduce dosage of the individual agents with concomitant reduction in the incidence and severity of side effects [4].

Earlier studies have advocated routine combination of long and short acting local anesthetics together, as it significantly attenuated the 1-hour rebound increase in pain scores seen after short acting anaesthesia alone [5]

Epidural analgesia after surgery in addition to providing patient comfort can facilitate accelerated recovery. This anaesthesia approach is labeled postoperative rehabilitation [6]. With this approach post surgical patient receive not only effective pain relief but also 


\section{Original Research Article}

immediate postoperative intake of oral nutrition, reduction in perioperative stress responses and organ dysfunction, avoidance of fatigue, early mobilization and postoperative discharge [7]. Studies have shown that Butorphanol has significant analgesic potency, narcotic antagonistic properties, anti -tussive effect, reversibility with naloxone and low physical dependence liability. The potency of Butorphanol was found to be approximately 5 times that of morphine and 40 times that of Meperidine[8].

Demographic data of both the groups were comparable. We observed faster onset as well as peak effect of both sensory and motor effect with group B patients as compared to group A patients $(\mathrm{p}<0.05)$. Similar finding of faster onset of sensory blockade was found in another study where 2 and $4 \mathrm{mg}$ of epidural Butorphanol has been used [9]. Lipid soluble opioids, such as Fentanyl and Sufentanylcross the dura and penetrate the cord quickly producing a rapid onset of action and it corresponds to a high CSF concentrationwhich occurs before the blood level is sufficiently high enough to be analgesic [10]. This may be the reason for faster onset of both sensory and motor effect with Butorphanol.

More water-soluble opioids like morphine have a slower onset of analgesia but a more prolonged duration action and side effects. Sedation score shows that majority of patients of both the groups were asleep but arousable. From our previous experience we have found that orthopedic patients demand sedation during central neuraxial blockade but in our study this was not the case. Thus, the sedative effect of Butorphanol was used to advantage intraoperatively.

Hemodynamic changes following epidural Butorphanol in both the groups were clinically and statistically insignificant $(\mathrm{p}>0.05)$. Previous workers have found that healthy volunteers receiving $0.03 \mathrm{mg} / \mathrm{kg}$ and $0.06 \mathrm{mg} / \mathrm{kg}$ of Butorphanol IV did not show any statistically significant hemodynamic changes $[11,12]$ but respiratory parameter shows that there was significant fall in respiratory rate from baseline in both the groups. Still it was never $<10 / \mathrm{min}$. Thus, none of the patients from either group had respiratory depression and reading on pulse - oximetry graph further supported this. Earlierstudy found that no patient developed a clinically important change in heart rate or blood pressure and none experienced a decrease in respiratory rate below $12 / \min [12]$.

The measurement of respiratory rate as an indication of drug induced respiratory depression is not as sensitive as the determination of minute ventilation or response to carbon dioxide.But we used respiratory rate rather than other measures of respiratory depression and our data are in agreement with those previously published for Butorphenol [13]. Epidural morphine and Butorphanol both are associated with a decreased central sensitivity to $\mathrm{CO} 2$ however duration of depression is shorter after Butorphanol than after Morphine.

Respiratory depression can occur with Butorphanol, but unlike morphine the dose-response curve for this effect is plateau-like or bell-shaped and higher doses $(>1$ or 2 $\mathrm{mg}$ in healthy subject) producing a lesser effect than lower doses, as it is not dose related [13]. None of the patients from either group experienced the well-known side effects of opioid like respiratory depression, pruritus, nausea/vomiting etc. Reason is Butorphanol a $\mathrm{k}$ receptor agonist and $\mathrm{m}$ agonist-antagonist, produces analgesia but fewer side effects. Its high lipid solubility for opioid receptor is additional factors that contribute to the paucity of side effects with its use [14].

Evaluating the postoperative analgesia according to visual analogue scale, group A patients had pain relief up to $8 \mathrm{hrs}$ and rescue analgesia was required between 8-10hrs as seen in table and graph. Group B patients had a relief up to $12 \mathrm{hrs}$ and rescue analgesia was required only after that period.

Thus the difference between group A and group B is significant $(p<0.05)$. This is also supported on evaluation with analgesia score. Thus, $3 \mathrm{mg}$ of epidural Butorphanol provides longer duration of postoperative analgesia in comparison to $2 \mathrm{mg}$ of the same drug.

We did not find any well-known complications of opioid. Earlier study had found high rate of pruritus $(43 \%)$ with epiduralmorphine as compared to epiduralButorphanol [15].

\section{Conclusion}

Newer synthetic opioid; Butorphanol can be used along with local anaesthetic solution via epidural route in lower limb orthopedic surgeries with effective intraoperative sedation and postoperative analgesia without fear of nausea/vomiting and respiratory depression. The comparison of two groups shows that 3 $\mathrm{mg}$ of Butorphanol provides faster onset and peak effect, with longer duration of analgesia postoperatively.

\footnotetext{
Funding: Nil, Conflict of interest: None Permission of IRB: Yes
} 


\section{References}

1. Petropoulos G, Siristatidis C, Salamalekis E, Creatsas G. Spinal and epidural versus general anesthesia for elective cesarean section at term: effect on theacid-base status of the mother and newborn. J Matern Fetal Neonatal Med. 2003 Apr;13(4):260-6. DOI:10.1080/jmf. 13.4.260.266.

2. Palacios QT, Jones MM, Hawkins JL, et al. Postcaesarean section analgesia: a comparison of epidural butorphanol and morphine. Can J Anaesth. 1991 Jan; 38(1):24-30. DOI:10.1007/BF03009159.

3. Graham AC, McClure JH. Quantitative assessment of motor block in labouring women receiving epidural analgesia. Anaesthesia. 2001 May;56(5):470-6.

4. Kaur J, Bajwa SJ. Comparison of epidural butorphanol and fentanyl as adjuvants in the lower abdominal surgery: A randomized clinical study. Saudi J Anaesth. 2014 Apr; 8(2):167-71. doi: 10.4103/1658354X.130687.

5. Del Pizzo A. A double-blind study on the effects of butorphanol compared with morphine in balanced anaesthesia. Can Anaesth Soc J. 1978 Sep;25(5):392-7.

6. Kehlet H. Multimodal approach to control postoperative pathophysiology and rehabilitation. $\mathrm{Br} \mathrm{J}$ Anaesth. 1997 May;78(5):606-17.

7. Rosenberg J, Kehlet H. [Surgical physiopathology. New results of importance for optimization of the postoperative course]. UgeskrLaeger. $2001 \mathrm{Feb}$ 12;163 (7): $908-12$.

8. Zacny JP, Lichtor JL, Thapar P, et al. Comparing the subjective, psychomotor and physiological effects of intravenous butorphanol and morphine in healthy volunteers. J Pharmacol Exp Ther. 1994 Aug;270(2): $579-88$.

9. Gupta R, Kaur S, Singh S, Aujla KS. A comparison of Epidural Butorphanol and Tramadol for Postoperative Analgesia Using CSEA Technique. J Anaesthesiol Clin Pharmacol. 2011 Jan;27(1):35-8.

10. Clotz MA, Nahata MC. Clinical uses of fentanyl, sufentanil, and alfentanil. Clin Pharm. 1991 Aug;10 (8):581-93.

11. Saxena AK, Arava SK. Current concepts in neuraxial administration of opioids and non opioids: An overview and future perspectives.Indian $J$ Anaesth. 2004 Feb; 48(1): 13-24.

12. Parikh GP, Veena SR, Vora K, et al. Comparison of epidural butorphanol versus epidural morphine in postoperative pain relief. Middle East J Anaesthesiol. 2014 Feb;22(4):371-6.

13. Abboud TK, Moore M, Zhu J, et al. Epidural butorphanol or morphine for the relief of post-cesarean section pain: ventilatory responses to carbon dioxide. AnesthAnalg. 1987 Sep;66(9):887-93.

14. Heel RC, Brogden RN, Speight TM, Avery GS. Butorphanol: a review of its pharmacological properties and therapeutic efficacy. DOI:10.2165/00003495-19781 6060-00001.

15. Gunter JB, McAuliffe J, Gregg T, et al. Continuous epidural butorphanol relieves pruritus associated with epidural morphine infusions in children. Paediatr Anaesth. 2000;10(2):167-72.

\section{How to cite this article?}

Kujur S, Kosam D. Comparison of two different doses of Epidural Butorphanol in Lower Limb Orthopedic Surgery. Int J Med Res Rev 2018; 6(07):360-366. doi:10.17511/ijmrr.2018.i07.04. 